\title{
Germinação de sementes de Ocotea odorifera (Vell.) Rohwer: temperátura de incubação e tratamentos pré-germinativos
}

\author{
Germination of Ocotea odorifera (Vell.) Rohwer seeds: incubation temperature and \\ pre-germinating treatments
}

\author{
Patricia Zanotelli ${ }^{1}$ e Camila Kissmann ${ }^{2}$ \\ ${ }^{1}$ Universidade Comunitária da Região de Chapecó, SC, Brasil \\ patricia.zanotelli@unochapeco.edu.br \\ ${ }^{2}$ Universidade Estadual Paulista Júlio de Mesquita Filho, SP, Brasil \\ camilakissmann@gmail.com
}

\begin{abstract}
Resumo
Ocotea odorifera é uma espécie nativa da Floresta Ombrófila Mista que está em perigo de extinção devido, sobretudo, à intensa exploração do óleo essencial extraído de sua madeira. As sementes de O. odorifera possuem dormência física e morfológica, o que dificulta a produção de mudas em viveiros comerciais. Esta pesquisa foi realizada com o objetivo de avaliar as respostas germinativas de sementes de Ocotea odorifera submetidas a diferentes tratamentos pré-germinativos, de baixo custo e fácil aplicação, sob temperatura constante $\left(25{ }^{\circ} \mathrm{C}\right)$ e alternada $\left(20-30{ }^{\circ} \mathrm{C}\right)$. Os tratamentos foram: desponte, imersão em água por 24 horas e matricondicionamento em areia úmida durante 7, 14, 21 e 28 dias além do tratamento controle. O experimento foi realizado em laboratório, em delineamento experimental inteiramente casualizado, em esquema fatorial 2 (temperaturas) $x 7$ (tratamentos) com três repetições de 100 sementes. As sementes de O. odorifera apresentaram melhor desempenho germinativo na temperatura de $25{ }^{\circ} \mathrm{C}$ em relação à temperatura de $20-30{ }^{\circ} \mathrm{C}$. A germinação das sementes submetidas aos tratamentos prégerminativos não diferiu da testemunha. Os resultados indicam que as sementes de O. odorifera não possuem dormência tegumentar, contrariando informações da literatura.
\end{abstract}

Palavras-chave: Canela-sassafrás; Dormência; Espécie nativa

\section{Abstract}

Ocotea odorifera is a native species of the Mixed Ombrophilous Forest that is endangered, mainly due to intense exploration of the essential oil extracted from its wood. The O. odorifera seeds have physical and morphological dormancy, which make more difficult the production of seedlings in commercial nurseries. This research was conducted in order to evaluate the germinative responses of Ocotea odorifera seeds subjected to different pregerminating treatments, of low-cost and ease of use, to overcome physical dormancy in the seeds of this species in laboratory conditions under constant $\left(25^{\circ} \mathrm{C}\right)$ and alternating $\left(20-30^{\circ} \mathrm{C}\right)$ temperature. The treatments were: coating cutting, immersion in water during 24 hours and matriconditioning in moist sand during 7, 14, 21 and 28 days beyond the control treatment. The experiment was conducted in the laboratory, in a completely randomized design, in a factorial scheme 2 (temperatures) $x 7$ (treatments) with three replications of 100 seeds. The O. odorifera seeds showed better germination performance at $25^{\circ} \mathrm{C}$ than at $20-30^{\circ} \mathrm{C}$. The germination of seeds submitted to different pre-germinative treatments did not differ from the control. The results show that $O$. odorifera seeds does not have physical dormancy, contradicting the literature information.

Keywords: Canela-sassafrás; Dormancy; Native species 


\section{Introdução}

As florestas nativas subtropicais da região sul do Brasil sofreram intensa redução na sua área durante o último século e ainda permanecem sob pressão exploratória (METZGER, 2009). Como resultado, muitas espécies florestais nativas tiveram sua população drasticamente reduzida, como por exemplo, a Ocotea odorifera (Vell.) Rohwer, popularmente conhecida como canela-sassafrás, canela-cheirosa ou sassafrás (CARVALHO, 2005).

Ocotea odorifera é uma espécie nativa da Floresta Ombrófila Mista que, desde o início da colonização, foi intensamente explorada pelo uso de seu óleo essencial, o safrol, o qual possui alto valor econômico e importância farmacêutica (MAAR e ROSENBROCK, 2012). Tal exploração fez com que, atualmente, a espécie seja descrita como em perigo de extinção no Livro Vermelho da Flora do Brasil (MARTINELLI e MORAES, 2013).

A curta longevidade das sementes de O. odorifera devido à recalcitrância (DAVIDE et al., 2003) dificulta a conservação ex situ da espécie. Além disso, segundo a literatura, as sementes de O. odorifera apresentam dormência tegumentar e embrionária (CARVALHO, 2005), o que dificulta a produção de mudas e a disponibilização da espécie em viveiros florestais. A superação da dormência das sementes de O. odorifera se dá mediante a utilização de ácido sulfúrico, porém tratamentos pré-germinativos que utilizam ácidos são dispendiosos e se mostram inviáveis para o uso em larga escala em viveiros florestais. Assim, faz-se necessário estudos de técnicas, de baixo custo e fácil aplicação, que aumentem o desempenho germinativo das sementes e/ou que possibilitem a superação da dormência quando presente, resultando em maior uniformidade na produção de mudas. Nesse contexto, os tratamentos de osmocondicionamento, hidrocondicionamento e matricondicionamento têm se mostrado eficazes para aumentar a germinação de sementes de diversas espécies de plantas cultivadas (MARCOS FILHO, 2005), porém os seus efeitos ainda são pouco estudados para sementes de espécies florestais.

A temperatura é um fator externo que exerce um importante papel no processo germinativo das sementes de espécies florestais nativas. De modo geral, para as espécies da Mata Atlântica, a temperatura ótima para germinação encontra-se entre $20^{\circ} \mathrm{C}$ e $30^{\circ} \mathrm{C}$ (BRANCALION et al., 2010). Para O. odorifera, as temperaturas mais adequadas para o desempenho germinativo das sementes são $25^{\circ} \mathrm{C}$ e $30^{\circ} \mathrm{C}$ (CETNARSKI FILHO e NOGUEIRA, 2005). Contudo, a germinação das sementes desta espécie sob temperaturas alternadas ainda não foi estudada. Segundo Brancalion et al. (2010), as temperaturas alternadas tendem a favorecer a germinação de espécies finais da sucessão florestal e contribuir na superação da dormência em espécies pioneiras. Nesse sentido, é possível que temperaturas alternadas melhorem o desempenho germinativo das sementes de O. odorifera, que é classificada como espécie secundária a clímax (CARVALHO, 2005).

Estudos que contribuem para o conhecimento sobre a biologia das espécies florestais são essenciais para a preservação destas, pois contribuem para a sua conservação ex situ. Assim, o objetivo deste trabalho foi avaliar o desempenho germinativo de sementes de Ocotea odorifera submetidas a diferentes tratamentos pré-germinativos, sob temperaturas constante e alternada.

\section{Material e método}

Os frutos de Ocotea odorifera foram coletados em área particular $\left(27^{\circ} 10^{\prime} 40.7^{\prime \prime} \mathrm{S} 052^{\circ} 39^{\prime} 55.9^{\prime \prime} \mathrm{W}\right)$ de Floresta Ombrófila Mista, localizada no município de Chapecó, Oeste de Santa Catarina, sul do Brasil. Frutos maduros foram coletados manualmente de 10 árvores matrizes, sendo o critério para a coleta a alteração da coloração da polpa de verde para roxo. Os frutos coletados foram levados para o Laboratório de Sementes da Universidade Comunitária da Região de Chapecó (Unochapecó), onde foram despolpados sob água corrente e com auxílio de uma peneira.

Após a coleta e despolpamento dos frutos foi realizada a caracterização do lote de sementes quanto ao teor de água, de acordo com as Regras para Análise de Sementes (BRASIL, 2009). Para a realização dos tratamentos prégerminativos, as sementes de O. odorifera foram previamente imersas em solução de hipoclorito de sódio $(\mathrm{NaClO}$ 2,5\%) por 1 minuto para desinfestação fúngica e, em seguida, lavadas em água corrente. Posteriormente, as sementes foram submetidas aos seguintes tratamentos pré-germinativos: 1 ) desponte (corte do tegumento no lado oposto ao embrião); 2) imersão em água a temperatura ambiente por 24 horas; 3) matricondicionamento em areia úmida a temperatura ambiente por sete dias; 4 ) matricondicionamento em areia úmida a temperatura ambiente por 14 dias; 5) matricondicionamento em areia úmida a temperatura ambiente por 21 dias; e 6) matricondicionamento em areia úmida a temperatura ambiente por 28 dias. As sementes que não receberam nenhum tratamento serviram como testemunha. O desponte foi realizado com auxílio de uma lâmina de aço, enquanto o matricondicionamento foi realizado com areia úmida, sendo as sementes dispostas entre camadas de areia, permanecendo à temperatura ambiente sobre a bancada do laboratório $\left( \pm 25^{\circ} \mathrm{C}\right)$. Após a aplicação dos tratamentos pré-germinativos, as sementes foram colocadas para germinar em caixas de acrílico transparentes (gerbox), parcialmente preenchidas com substrato vermiculita umedecido com água destilada. As caixas foram dispostas em câmaras de germinação reguladas 
à temperatura de $25^{\circ} \mathrm{C}$ e $20-30{ }^{\circ} \mathrm{C}(12 \mathrm{~h} / 12 \mathrm{~h})$, ambas sob luz contínua (lâmpadas fluorescentes, $\left.80 \mu \mathrm{mol} \mathrm{m}-2 \mathrm{~s}-1\right)$.

A contagem do número de sementes germinadas foi efetuada diariamente até a obtenção da estabilidade na curva de germinação das sementes, de acordo com as prescrições das Regras para Análise de Sementes (BRASIL, 2009). Foram consideradas como plântulas normais aquelas que apresentaram raiz primária igual ou superior a dois centímetros de comprimento. Os dados da contagem foram utilizados para calcular a porcentagem final de germinação, obtida por meio da divisão do somatório do número de sementes germinadas pelo total de sementes e multiplicando-se o valor por 100; o índice de velocidade de germinação (IVG) - através da fórmula IVG $=(\mathrm{G} 1 /$ $\mathrm{N} 1)+(\mathrm{G} 2 / \mathrm{N} 2)+(\mathrm{G} 3 / \mathrm{N} 3)+\ldots+(\mathrm{Gn} / \mathrm{Nn})$, em que G1, G2, G3, ..., Gn = número de sementes germinadas computadas na primeira, segunda, terceira e última contagem; $N 1, N 2, N 3, \ldots, N n=$ número de dias da semeadura à primeira, segunda, terceira e última contagem (MAGUIRE, 1962); e o tempo médio de germinação (TMG) - através da fórmula onde $\mathrm{TMG}=\Sigma(\mathrm{ni}$ ti $) / \Sigma \mathrm{ni}$, em que ni = número de sementes germinadas no intervalo entre cada contagem e ti = tempo decorrido entre o início da germinação e a i-ésima contagem (LABOURIAU, 1983). O experimento foi realizado em delineamento inteiramente casualizado (DIC) em esquema fatorial 7 (tratamentos pré-germinativos) e 2 (temperaturas), com três repetições (gerbox) de 100 sementes por tratamento. Os dados foram analisados por Two-Way ANOVA e as médias foram comparadas pelo teste de Tukey $(\mathrm{P} \leq 0.05)$.

\section{Resultados e discussão}

As sementes de Ocotea odorifera apresentaram teor de água igual a 30,7\% no momento em que foram coletadas (logo após a dispersão) e utilizadas nos testes de germinação. Houve interação significativa entre os fatores somente para o tempo médio de germinação (Tabela 1).

Tabela 1 - Resumo da análise de variância para porcentagem de germinação (\%G), índice de velocidade de germinação (IVG) e tempo médio de germinação (TMG) de sementes de Ocotea odorifera (Vell.) Rohwer

\begin{tabular}{l|c|c|c|c|c|c|c}
\hline Fator de variação & GL & \multicolumn{2}{|c|}{ G $(\%)$} & \multicolumn{2}{c|}{ IVG } & \multicolumn{2}{c}{ TMG } \\
\hline & & F & P & F & P & F & P \\
\hline Temperatura & 1 & 8,16 & $0,008^{* *}$ & 28,829 & $<0,001^{* *}$ & 62,572 & $<0,001^{* *}$ \\
\hline Tratamentos & 6 & 4,40 & $0,003^{* *}$ & 7,296 & $<0,001^{* *}$ & 18,494 & $<0,001^{* *}$ \\
\hline $\begin{array}{l}\text { Temperatura } x \\
\text { Tratamentos }\end{array}$ & 6 & 0,52 & $0,786^{\text {ns }}$ & 0,512 & $0,794^{\text {ns }}$ & 3,278 & $0,014^{* *}$ \\
\hline CV (\%) & \multicolumn{3}{|c|}{13,7} & & 20 & \multicolumn{2}{c|}{10,2} \\
\hline
\end{tabular}

ns = não significativo; ${ }^{* *}=$ significativo ao nível de $5 \%$ de probabilidade pelo teste $\mathrm{F}$

Analisando-se os fatores isoladamente, observa-se que a porcentagem de germinação e o IVG diferiram significativamente entre as temperaturas, sendo que a temperatura de $25^{\circ} \mathrm{C}$ proporcionou maior velocidade e porcentagem de sementes germinadas em relação à temperatura de 20-30 ${ }^{\circ} \mathrm{C}$ (Tabela 2). A temperatura $20-30{ }^{\circ} \mathrm{C}$ não resultou em maior germinação de sementes de O. odorifera e, de modo similar, Bilia et al. (1998) observaram que as sementes de Ocotea corymbosa (Meissn.) Mez apresentaram maior germinação sob temperatura constante de $30{ }^{\circ} \mathrm{C}$ do que sob $20-30{ }^{\circ} \mathrm{C}$.

Tabela 2 - Porcentagem final de sementes germinadas (\%G) e índice de velocidade de germinação (IVG) de sementes de Ocotea odorifera (Vell.) Rohwer colocadas para germinar em câmaras de germinação sob temperaturas de $25^{\circ} \mathrm{C}$ e $20-30^{\circ} \mathrm{C}$ com luz contínua

\begin{tabular}{l|c|c}
\hline Temperatura & G (\%) & IVG \\
\hline $25^{\circ} \mathrm{C}$ & $85,05 \mathrm{a}$ & $1,94 \mathrm{a}$ \\
\hline $20-30^{\circ} \mathrm{C}$ & $77,29 \mathrm{~b}$ & $1,58 \mathrm{~b}$ \\
\hline
\end{tabular}

Médias seguidas de letras minúscula distintas na coluna são estatisticamente diferentes entre si pelo teste de Tukey, a 5\% de significância.

Em relação aos tratamentos para superação de dormência, a porcentagem de germinação diferiu significativamente entre os tratamentos, onde os matricondicionamentos por 14 e 21 dias apresentaram as maiores porcentagens de germinação, as quais não diferiram entre si, mas superaram a imersão em água por 24 horas. Os demais tratamentos 


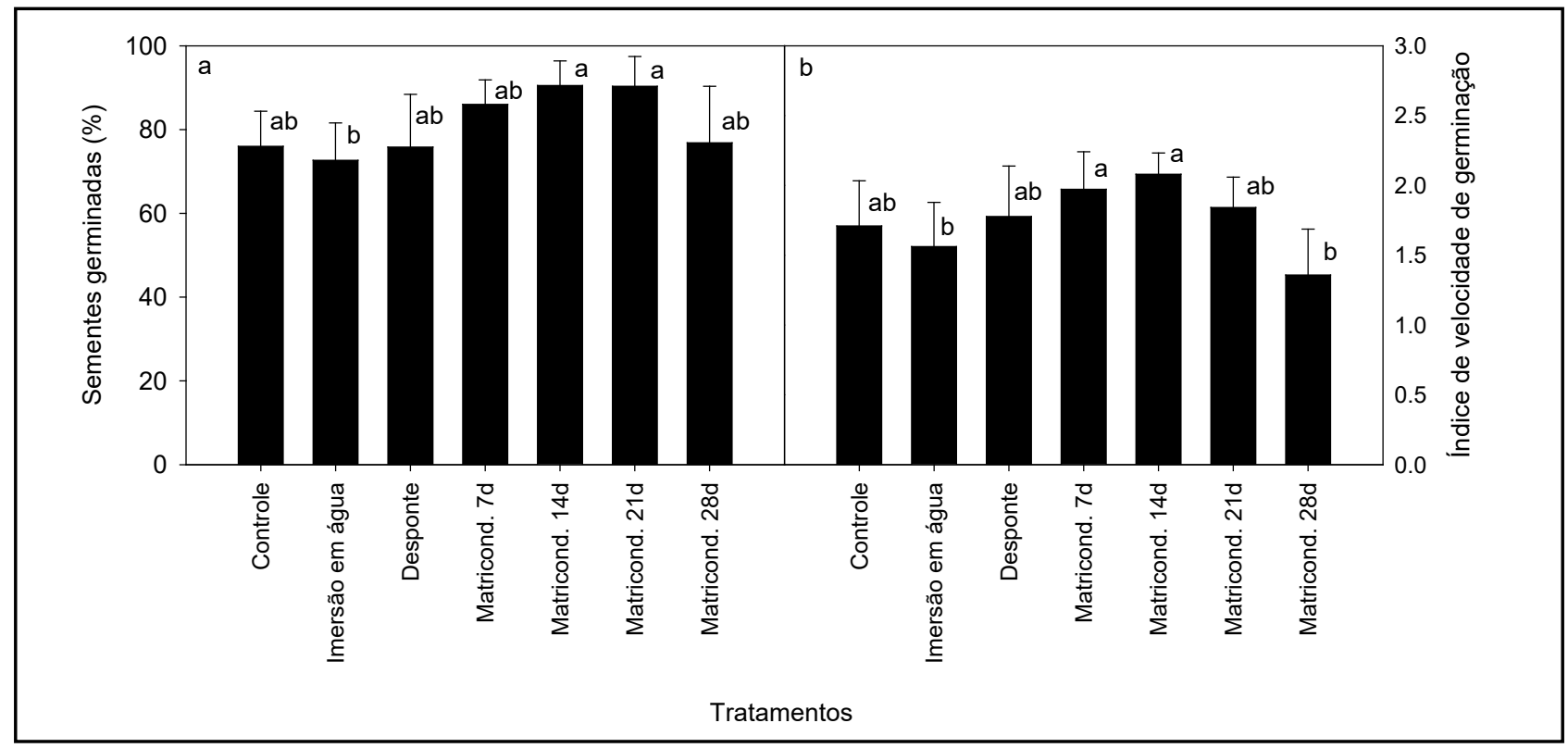

Figura 1 - Porcentagem de germinação (a) e índice de velocidade de germinação (b) de sementes Ocotea odorifera (Vell.) Rohwer submetidas a diferentes tratamentos pré-germinativos (Matricond. $7 \mathrm{~d}, 14 \mathrm{~d}, 21 \mathrm{~d}, 28 \mathrm{~d}=$ matricondicionamento por $7,14,21$ e 28 dias respectivamente). Colunas representam os valores médios de repetições de cada tratamento e as barras indicam o desvio padrão. Médias seguidas por letras distintas diferem entre si ao nível de significância de 5\% pelo teste de Tukey

- testemunha, desponte e matricondicionamento por sete e 28 dias - apresentaram valores intermediários para a porcentagem de germinação não diferindo da testemunha e da imersão em água por 24 horas (Figura 1a).

O índice de velocidade de germinação também diferiu significativamente entre os tratamentos (Figura 1b). Os índices de velocidade de germinação das sementes submetidas aos matricondicionamentos por sete e 14 dias foram superiores ao observado para as sementes em imersão em água e submetidas ao matricondicionamento por 28 dias, enquanto os demais tratamentos apresentaram valores intermediários de IVG.

Embora tanto o matricondicionamento por 14 como por 21 dias apresentaram germinação superior a 90\%, quando considerada a velocidade de germinação, o matricondicionamento por 14 dias mostrou-se melhor que o de 21 dias para as sementes de $\mathrm{O}$. odorifera. O condicionamento apresenta vantagens em relação à imersão em água, pois a presença de partículas sólidas (com potencial mátrico) implica em uma embebição mais lenta das sementes, o que é uma vantagem uma vez que a rápida embebição favorece a ocorrência de injúrias às sementes (MARCOS FILHO, 2005). Segundo este autor, o condicionamento de sementes é desejável especialmente para sementes com baixo teor de água, pois quando sementes muito secas sofrem rápida embebição liberam solutos e macromoléculas comprometendo a sua qualidade fisiológica. No caso de O. odorifera as sementes são dispersas com elevado teor de água por serem recalcitrantes, porém ainda assim, o condicionamento por 14 e 21 dias proporcionou germinação e IVG superiores em relação às sementes imersas em água. Entretanto, os tratamentos de osmocondicionamento não proporcionaram \%G e IVG superior às sementes não tratadas (Figura 1).

A dormência tegumentar em espécies de Ocotea frequentemente é superada com o uso de ácido sulfúrico (H2SO4). Carvalho (2005) recomenda a escarificação em ácido sulfúrico concentrado por cinco minutos associada à estratificação em areia úmida por 60 dias para a superação de dormência das sementes de O. odorifera. Kalil Filho et al. (2004) testaram escarificação em ácido sulfúrico 70\% por 3 minutos para a superação da dormência de O. porosa e obtiveram baixos índices de germinação (9,70\% a 18,19\%). Silva et al. (2002) utilizou ácido sulfúrico 30\% de concentração em diferentes tempos e obtiveram germinação em torno de $40 \%$ para sementes de O. puberula. No presente trabalho as sementes de O. odorifera apresentaram elevado percentual de germinação (superior a 90\%) com o matricondicionamento por 14 e 21 dias, sendo este valor superior ao observado para sementes submetidas a desponte. Inclusive as sementes testemunhas apresentaram germinação estatisticamente igual às sementes submetidas ao desponte ou aos tratamentos de matricondicionamento. Esses dados sugerem que as sementes de O. odorifera não possuem dormência tegumentar, contrariando informações da literatura (CARVALHO, 2005).

Segundo Baskin e Baskin (2004) a dormência física das sementes é comumente confundida com dormência fisiológica, onde a germinação não ocorre devido à restrição imposta pelas camadas do endosperma que envolvem o embrião, impedindo o seu crescimento e a protrusão da raiz primária pelo tegumento. A dormência física (ou tegumentar), por sua vez, é causada pela presença de células paliçádicas no tegumento das sementes que impedem 
a entrada de água e tem sido amplamente relatada para espécies de Fabaceae (OLIVEIRA et al., 2012; ATAÍDE et al., 2013; PEREIRA et al., 2104) embora também ocorra em outras famílias como Malvaceae, Anacardiaceae e Nelumbonaceae (BASKIN et al., 2000). É possível que algumas espécies de Lauraceae apresentem dormência física devido às características do tegumento (BASKIN e BASKIN, 2004), porém Finch-Savage e Leubner-Metzgeransley (2006) reportaram apenas a ocorrência de dormência fisiológica e sementes não dormentes na família. De fato, Bilia et al. (1998) observaram que embriões excisados (sem endocarpo/tegumento) de Ocotea odorifera apresentaram germinação superior à testemunha e aos diásporos submetidos a algum tipo de escarificação, sugerindo a presença de dormência fisiológica. Já Pires et al. (2009) observaram ausência de dormência em sementes de Ocotea pulchella (Nees) Mez. Essas observações combinadas aos dados obtidos no presente estudo sugerem que as sementes de Ocotea odorifera não possuem dormência causada pelo tegumento e que as baixas taxas de germinação de O. porosa tratadas com ácido sulfúrico estejam relacionada não à ausência de superação da dormência mas sim a danos causados pelo ácido sulfúrico ao embrião (Kalil Filho et al., 2004).

Em relação ao tempo médio de germinação foi observada interação significativa entre as temperaturas e os tratamentos pré-germinativos para o tempo médio de germinação (Tabela 1). O tempo médio de germinação das sementes submetidas ao matricondicionamento por 14, 21 ou 28 dias não diferiu entre as temperaturas, porém para os demais tratamentos pré-germinativos, a temperatura de $25^{\circ} \mathrm{C}$ apresentou menor tempo médio para germinação em relação à temperatura de $20-30{ }^{\circ} \mathrm{C}$ (Tabela 3). Para $25{ }^{\circ} \mathrm{C}$ o matricondicionamento por 28 dias proporcionou tempo médio para germinação superior aos demais tratamentos. Já para a temperatura de 20-30 ํㅡ, o matricondiconamento por 28 dias apresentou tempo médio de germinação superior aquele observado para testemunha, desponte e matricondicionamentos por sete e 14 dias, porém semelhante TMG observado para imersão em água e matricondicionamento por 21 dias. Em ambas as temperaturas, com exceção do matricondicionamento por 28 dias, o TMG dos demais tratamentos pré-germinativos não diferiram do TMG apresentado pela testemunha (Tabela 3).

Tabela 3 - Tempo médio de germinação (TMG) de sementes de Ocotea odorifera (Vell.) Rohwer submetidas a diferentes temperaturas e tratamentos para superação de dormência

\begin{tabular}{l|c|c}
\hline \multicolumn{1}{c|}{ Tratamento } & $25^{\circ} \mathrm{C}$ & $20-30{ }^{\circ} \mathrm{C}$ \\
\hline Testemunha & $42,87 \mathrm{~B} \mathrm{bc}$ & $49,73 \mathrm{~A} \mathrm{~b}$ \\
\hline Imersão em água por 24h & $42,63 \mathrm{~B} \mathrm{c}$ & $51,80 \mathrm{~A} \mathrm{ab}$ \\
\hline Desponte & $40,27 \mathrm{~B} \mathrm{c}$ & $47,90 \mathrm{~A} \mathrm{~b}$ \\
\hline Matricondicionamento por 7 dias & $42,90 \mathrm{~B} \mathrm{bc}$ & $48,87 \mathrm{~A} \mathrm{~b}$ \\
\hline Matricondicionamento por 14 dias & $43,80 \mathrm{~A} \mathrm{bc}$ & $45,50 \mathrm{~A} \mathrm{~b}$ \\
\hline Matricondicionamento por 21 dias & $48,13 \mathrm{~A} \mathrm{~b}$ & $51,07 \mathrm{~A} \mathrm{ab}$ \\
\hline Matricondicionamento por 28 dias & $54,03 \mathrm{~A} \mathrm{a}$ & $55,40 \mathrm{~A} \mathrm{a}$ \\
\hline
\end{tabular}

Médias seguidas de mesma letra minúscula na coluna e maiúscula na linha são estatisticamente iguais entre si pelo teste de Tukey, a 5\% de significância.

\section{Conclusões}

Os resultados do presente trabalho indicam ausência de dormência tegumentar em sementes de Ocotea odorifera. O uso dos tratamentos de desponte, imersão das sementes em água e matricondicionamento não se justifica uma vez que estes não diferiram da testemunha. Os resultados denotam a necessidade de estudos futuros integrando fisiologia e anatomia para verificar a existência de dormência tegumentar relatada na literatura para esta espécie. Com relação às temperaturas, a temperatura constante de $25^{\circ} \mathrm{C}$ é mais favorável à germinação das sementes em relação à temperatura alternada de $20-30{ }^{\circ} \mathrm{C}$.

\section{Referências}

ATAÍDE, G. M.; BICALHO, E. M.; DIAS, D. C. F. S.; CASTRO, R. V. O.; ALVARENGA, E. M. Superação da dormência das sementes de Delonix regia (Bojer ex Hook.) Raf. Rev. Árvore 2013;37(6):1145-1152.

BASKIN, J. M.; BASKIN, C. C.; LI, X. Taxonomy, anatomy and evolution of physical dormancy in seeds. Plant Species Biology 2000;(15):139-152. 
BASKIN, J. M.; BASKIN, C. C. A classification system for seed dormancy. Seed Sci. Res. 2004;(14): 1-16.

BILIA, D. A. C.; BARBEDO, C. J.; MALUF, A. M. Germinação de diásporos de canela (Ocotea corymbosa (Meissn.) Mez - Lauraceae) em função da temperatura, do substrato e da dormência. Rev. Bras. Sementes 1998;(20):189-194.

BRANCALION, P. H. S., NOVEMBRE, A. D. L. C.; RODRIGUES, R. R. Temperatura ótima de germinação de sementes de espécies arbóreas brasileiras. Rev. Bras. Sementes 2010;32(4): 15-21.

BRASIL. Ministério da agricultura e da Reforma Agrária. Regras para a análise de sementes. Brasília, 2009. 399 p.

CARVALHO, P. E. R. Circular Técnica 110 - Canela-sassafrás. Colombo: Embrapa. 2005. 12 p.

CETNARSKI FILHO, R.; NOGUEIRA, A. C. Influência da temperatura na germinação de diásporos de Ocotea odorifera (Vellozo) Rohwer (Canela-sassafrás). Ciênc. Florest. 2005;15(2):191-198.

DAVIDE, A. C.; CARVALHO, L. R. C.; CARVALHO, M. L. M., GUIMARAES, R. M. Classificação fisiológica de sementes de espécies florestais pertencentes à família Lauraceae quanto à capacidade de armazenamento. Cerne 2003;9(1):29-35.

FINCH-SAVAGE, W. E.; LEUBNER-METZGER, G. Seed dormancy and the control of germination. New Phytol. 2006;(171): 501-523.

KALIL FILHO, A.N.; SOUSA, V.A.; MARZOLLO, L.G.; HIRANO, E. Dinâmica da germinação de sementes de progênies de populações de imbuia (Ocotea porosa Nees et Martius ex. Ness, Lauraceae) do Paraná e de Santa Catarina. Bol. Pesq. Fl. 004;(48):121-128.

LABOURIAU, L. G. A germinação das sementes. Washington: Secretaria da OEA. 1983. 174 p.

MAAR, J. H.; ROSENBROCK, L. C. C. A química fina que poderia ter sido: a extração de óleo de sassafrás e de safrol no alto e médio vale do Itajaí. Sci. Stud. 2012;10(4):799-820.

MAGUIRE, J. D. Speed of germination aid in selection and evaluation for seedling emergence and vigor. Crop Sci. 1962;(2): 176-177.

MARCOS FILHO, J. Fisiologia de sementes de plantas cultivadas. Piracicaba: Fealq. 2005.495 p.

MARTINELLI, G.; MORAES, M. A. Livro Vermelho da Flora do Brasil. Rio de Janeiro: Andrea Jakobsson / Instituto de Pesquisas Jardim Botânico do Rio de Janeiro. 2013. 1100 p.

2METZGER, J. P. Conservation issues in the Brazilian Atlantic Forest. Biol. Conserv.2009;(142):1138-1140.

OLIVEIRA, A. K. M.; RIBEIRO, J. W. F.; PEREIRA, K. C. L.; RONDON, E. V.; BECKER, T. J. A.; BARBOSA, L. A. Superação de dormência em sementes de Parkia gigantocarpa (Fabaceae - Mimosidae). Ciênc. Florest. 2012; 22(3): 533-540.

PEREIRA, V. J.; SANTANA, D. G.; LOBO, G. A.; BRANDÃO, N. A. L.; SOARES, D. C. P. Eficiência dos tratamentos para a superação ou quebra de dormência de sementes de Fabaceae. Rev. de Ciências Agrárias 2014; 37(2):187-197.

PIRES, L A. A; CARDOSO, V. J. M.; JOLY, C. A. RODRIGUES, R.R. Germination of Ocotea pulchella (Nees) Mez (Lauraceae) seeds in laboratory and natural restinga environment conditions. Braz. J. Biol. 2009; 69(3):935-942.

SILVA, A. C.; PORTELA, O.; LORDELLO, A. L. L.; NOGUEIRA, A. C. Efeito do pH sobre o grau de germinação de sementes de Ocotea puberula (Lauraceae). Visão Acadêmica 2002;(3):19-22. 